\title{
Community-based rehabilitation intervention for people with schizophrenia in Ethiopia (RISE): results of a 12-month cluster-randomised controlled trial
}

\author{
Laura Asher, Rahel Birhane, Helen A Weiss, Girmay Medhin, Medhin Selamu, Vikram Patel, Mary De Silva, Charlotte Hanlon, Abebaw Fekadu
}

\section{Summary}

Background Community-based rehabilitation (CBR) is recommended to address the social and clinical needs of people with schizophrenia in resource-poor settings. We evaluated the effectiveness of CBR at reducing disability at 12 months in people with schizophrenia who had disabling illness after having had the opportunity to access facilitybased care for 6 months

Methods This cluster-randomised controlled trial was conducted in a rural district of Ethiopia. Eligible clusters were subdistricts in Sodo district that had not participated in the pilot study. Available subdistricts were randomised (in a 1:1 ratio) to either the intervention group (CBR plus facility-based care) or to the control group (facility-based care alone). An optimisation procedure (accounting for the subdistrict mean WHO Disability Assessment Schedule (WHODAS) score and the potential number of participants per subdistrict) was applied for each of the eight health facilities in the district. An independent statistician, masked to the intervention or control label, used a computer programme to randomly choose the allocation sequence from the set of optimal ones. We recruited adults with disabling illness as a result of schizophrenia. The subdistricts were eligible for inclusion if they included participants that met the eligibility criteria. Researchers recruiting and assessing participants were masked to allocation status. Facility-based care was a task-shared model of mental health care integrated within primary care. CBR was delivered by lay workers over a 12-month period, comprising of home visits (psychoeducation, adherence support, family intervention, and crisis management) and community mobilisation. The primary outcome was disability, measured with the proxy-rated 36-item WHODAS score at 12 months. The subdistricts that had primary outcome data available were included in the primary analysis. This study is registered with ClinicalTrials.gov, NCT02160249.

Findings Enrolment took place between Sept 16, 2015 and Mar 11, 2016. 54 subdistricts were randomised (27 to the CBR plus facility-based care group and 27 to the facility-based care group). After exclusion of subdistricts without eligible participants, we enrolled 79 participants (66\% men and 34\% women) from 24 subdistricts assigned to CBR plus facility-based care and 87 participants (59\% men and 41\% women) from 24 subdistricts assigned to facilitybased care only. The primary analysis included 149 (90\%) participants in 46 subdistricts (73 participants in 22 subdistricts in the CBR plus facility-based care group and 76 participants in 24 subdistricts in the facility-based care group). At 12 months, the mean WHODAS scores were $46 \cdot 1$ (SD 23.3) in the facility-based care group and $40.6(22.5)$ in the CBR plus facility-based care group, indicating a favourable intervention effect (adjusted mean difference $-8 \cdot 13$ [95\% CI $-15 \cdot 85$ to $-0 \cdot 40]$; $p=0 \cdot 039$; effect size $0 \cdot 35$ ). Four (5\%) CBR plus facility-based care group participants and nine (10\%) facility-based care group participants had one or more serious adverse events (death, suicide attempt, and hospitalisation).

Interpretation CBR delivered by lay workers combined with task-shared facility-based care, was effective in reducing disability among people with schizophrenia. The RISE study CBR model is particularly relevant to low-income countries with few mental health specialists.

Funding Wellcome Trust.

Copyright (C) 2022 The Author(s). Published by Elsevier Ltd. This is an Open Access article under the CC BY 4.0 license.

\section{Introduction}

Schizophrenia is a global mental health priority due to the high levels of associated disability, poverty, premature mortality, and human rights abuses. ${ }^{1}$ In low-income and middle-income countries (LMICs), these adverse effects are amplified by the inadequacy and inaccessibility of existing formal care systems. In low-income countries, there are severe shortages of mental health specialists, who are usually concentrated in urban centres. As a result, $89 \%$ of people with schizophrenia in low-income countries do not receive evidence-based treatment. ${ }^{2}$ For many people with schizophrenia, functional recovery is
Lancet Glob Health 2022; 10: e530-42

See Comment page e457

Lifespan and Population Health Unit, School of Medicine, University of Nottingham, Nottingham, UK (L Asher PhD); WHO Collaborating Centre for Mental Health Research \& Capacity Building, Department of Psychiatry, School of Medicine, College of Health Sciences (R Birhane MSC, M Selamu PhD, C Hanlon PhD, Prof A Fekadu PhD) and Akililu Lemma Institute of Pathobiology (G Medhin PhD) and Centre for Innovative Drug Development and Therapeutic Trials for Africa (M Selamu, C Hanlon, Prof A Fekadu), Addis Ababa University, Addis Ababa, Ethiopia; MRC International Statistics and Epidemiology Group, London School of Hygiene and Tropical Medicine, London, UK

(Prof H A Weiss PhD); Department of Global Health and Social Medicine, Harvard Medical School

(Prof V Patel PhD) and Harvard Chan School of Public Health (Prof V Patel), Harvard University, Boston, MA, USA; The Wellcome Trust, London, UK (M De Silva PhD); Centre for Global Mental Health, Department of Health Service and Population Research, Institute of Psychiatry, Psychology and Neuroscience, King's College London, London, UK (C Hanlon); Department of Global Health \& Infection, Brighton and Sussex Medical School, Brighton, UK (Prof A Fekadu)

Correspondence to: Dr Laura Asher, Lifespan and Population Health Unit, School of Medicine, University of Nottingham,

Nottingham NG5 1PB, UK laura.asher@nottingham.ac.uk 
Research in context

\section{Evidence before this study}

A previous systematic review assessing evidence from randomised controlled trials (RCTs) published before 18 April, 2016, identified 11 RCTs in China, India, Iran, South Africa, and Turkey. Interventions included psychoeducational interventions, multi-component rehabilitation-focused interventions, and case management interventions; and with one exception they were delivered by specialists such as psychiatrists and mental health social workers. The findings were that community-based psychosocial interventions in low-income and middle-income countries (LMICs) are effective in improving symptoms and functioning and reducing hospital admissions in people with schizophrenia. As an update, we searched the Medline and PsychInfo databases from Jan 1, 2016, to March 12, 2021, using the terms "schizophrenia" or "mental disorders" and related terms; and "CBR" or "psychiatric rehabilitation" and related terms; and LMICs, as defined by the World Bank. Two additional RCTs $(n=327$ and $n=60)$ and one randomised pilot study $(n=57)$ were identified; they were all were set in China. Intervention components included psychoeducation, supportive counselling, family support, social skills training, and vocational skills training as part of the Clubhouse model. Two were delivered in community rehabilitation or health centres and one was delivered through home visits. All three trials found positive intervention effects on symptom severity, readmissions, and functioning. Across the systematic review and updated search, we identified no RCTs conducted in low-income countries, none in which the intervention was delivered as an adjunct to task-shared care, and only one study in which the intervention was delivered by lay workers. Employment assistance, raising community awareness, and signposting to community resources featured in one, two, and five studies respectively; to our knowledge no trial has incorporated active mobilisation of community members or organisations to support individuals with schizophrenia.

\section{Added value of this study}

To our knowledge, the RISE trial is the first RCT to evaluate the effectiveness of any type of psychosocial intervention for people with schizophrenia in a low-income country, and it is the first to assess the effectiveness of comprehensive community-based rehabilitation (CBR) for schizophrenia, including a structured community mobilisation component, in any setting globally. We found that CBR delivered by lay workers combined with facility-based care delivered predominantly in primary care was effective in reducing disability (particularly participation and social interactions), symptom severity, and caregiver tension and worrying; and effective in increasing antipsychotic medication adherence and attendance to facility-based care for mental health among people with schizophrenia at 12 months follow-up. The use of lay workers and non-specialist supervisors to deliver CBR enhances the minimal evidence on task-shared approaches to the care of people with schizophrenia and demonstrates that psychosocial support can be successfully delivered in resource-poor settings.

\section{Implications of all the available evidence}

In LMICs, community-based psychosocial interventions should be provided as an adjunct to facility-based treatment services providing access to antipsychotic medication. Combining psychosocial and pharmacological support is likely to produce the best treatment outcomes in terms of functional recovery and symptom severity. The intervention content and delivery personnel can be tailored to the resources available and the social context. Where there are few mental health specialists, lay workers can successfully provide psychosocial support as an adjunct to task-shared facility-based care. made more achievable with psychosocial rehabilitation in addition to pharmacological treatments; yet, psychosocial support is absent in most LMICs. ${ }^{3}$

Community-based rehabilitation (CBR) is a rights-based approach that is successfully used to support the rehabilitation and social inclusion of people with disabilities in LMICs. ${ }^{4}$ CBR champions a social model of disability, which states that disability is a product of both the environment and illness. It therefore aims to reduce disability through shaping the social world, using community mobilisation, and individual and family support. Alongside facility-based care and antipsychotic medication, delivered predominantly in primary care, CBR is recommended by WHO as a suitable psychosocial intervention for people with schizophrenia in LMICs. ${ }^{5}$ As CBR can be delivered by lay workers, ${ }^{4}$ it offers an affordable and accessible means to address the complex social, economic, and clinical needs of people with schizophrenia in resource-poor settings.
Community-based psychosocial interventions positively affect symptom severity, functioning, and hospital admissions among people with schizophrenia in LMICs. ${ }^{3}$ Research to date has two major limitations. First, all randomised trials to date were set in middle-income countries as an adjunct to well-resourced and accessible mental health care such as free antipsychotic medication and access to psychiatrists; and with one exception, ${ }^{6}$ none were delivered by lay workers. Second, with some exceptions, ${ }^{7.8}$ there has been little evaluation of the community mobilisation aspects of CBR or similar models. ${ }^{3}$

To address this evidence gap, we developed the Rehabilitation Intervention for People with Schizophrenia in Ethiopia (RISE) CBR intervention over an 18-month formative phase, ${ }^{9}$ then demonstrated its acceptability and feasibility in a 12-month pilot study. ${ }^{10}$ The RISE intervention was designed to meet the needs of people with schizophrenia in a rural Ethiopian district, a 
low-income setting with poor mental health care infrastructure and high poverty levels, which can impede care engagement and recovery. Unlike previous evaluations, CBR was devised as an adjunct to task-shared facilitybased care for schizophrenia, integrated within primary health-care centres, and was not supervised by mental health specialists. This facility-based model was implemented as part of the Programme for Improving Mental Health Care (PRIME). ${ }^{11}$ A distinctive component of the RISE intervention is its aim to shape individuals' social environment by enhancing community support and reducing stigmatising attitudes. ${ }^{4}$

The aim of this trial was to evaluate the effectiveness of CBR plus facility-based care compared with facility-based care alone at reducing disability at 12 months in people with schizophrenia. We focused on individuals who did not respond to or engage with treatment, to reflect the target group for CBR if it were scaled up in a resourcepoor setting.

\section{Methods}

\section{Study design and participants}

We conducted a cluster-randomised controlled trial in Sodo district, Gurage Zone, Southern Nations, Nationalities, and Peoples' Region in Ethiopia. Sodo district has a total population of 170000 people in 58 subdistricts. It is a socioeconomically deprived area with a largely agrarian economy, approximately 55\% literacy, and several remote rural areas. Primary care is delivered by nurses and health officers at seven health centres and one primary hospital. Care costs are usually out-of-pocket with a fee waiver available for the poorest. The study protocol was previously published ${ }^{12}$ (appendix pp 1-2 for amendments). Ethics approval was obtained from Institutional Review Boards at the London School of Hygiene \& Tropical Medicine, Addis Ababa University College of Health Sciences, and the Ethiopian National Research Ethics Review Committee.

Randomisation units were subdistricts of Sodo district. We identified 54 available subdistricts after subtracting the four pilot subdistricts. ${ }^{10}$ Subdistricts were excluded at screening and enrolment stages if no eligible participants were identified (figure). People with suspected schizophrenia in Sodo district were identified by PRIME using key community informants and health-extension workers who had received half a day of training in the typical presentations of schizophrenia (ie, the key informant method). This information was added to a database. Trained psychiatric nurses in the PRIME study used the Operational Criteria for Research (OPCRIT) diagnostic interview (which applies Diagnostic and Statistical Manual of Mental Disorders fourth edition [DSM-IV] criteria), ${ }^{13}$ and those with a confirmatory diagnosis of schizophrenia were recruited to the PRIME study. Facility-based care was available for people in the PRIME study with a confirmed diagnosis of schizophrenia. The PRIME study started 6 months before RISE trial

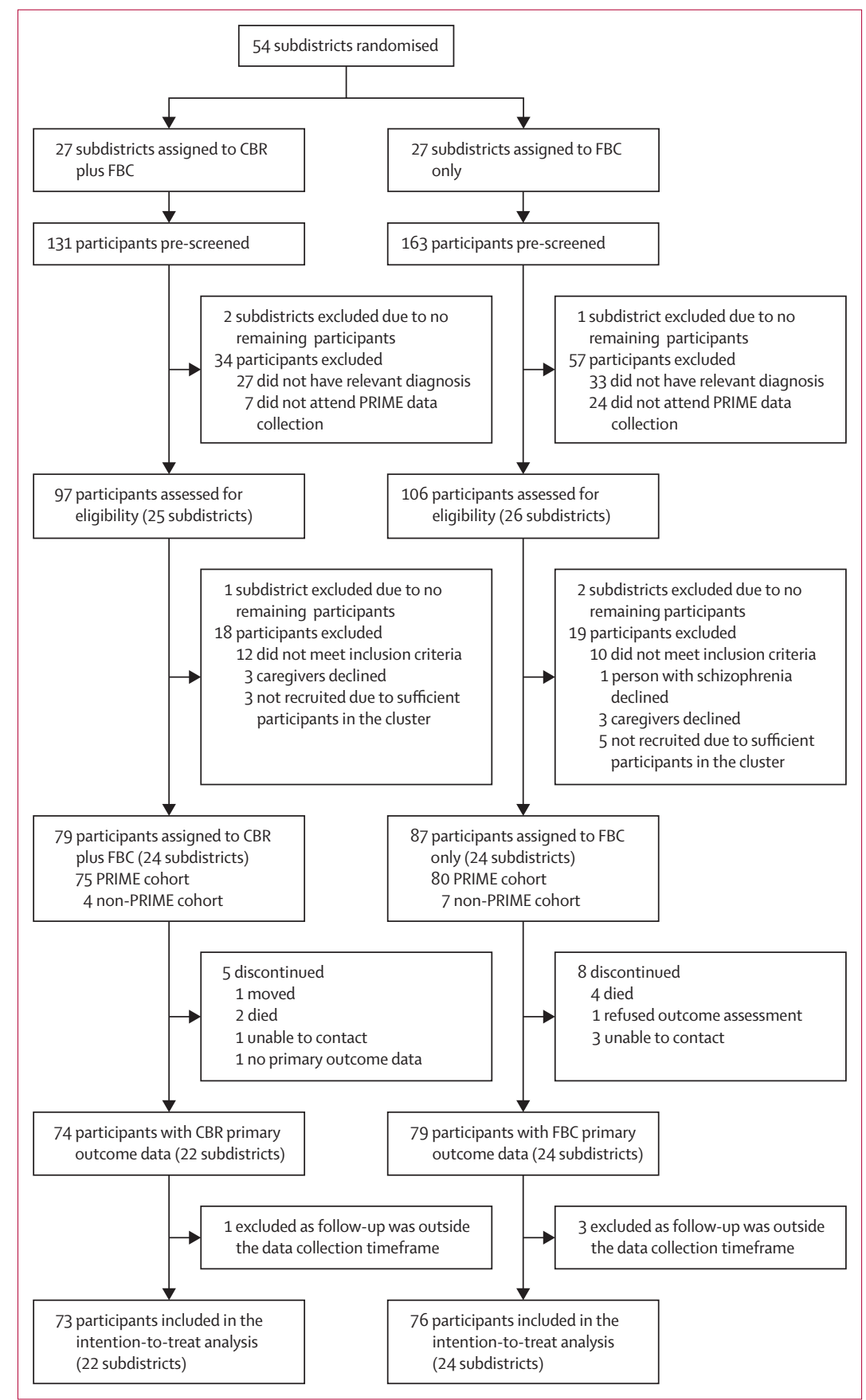

Figure: Trial profile

CBR=community-based rehabilitation. $\mathrm{FBC}=$ facility-based care.

recruitment. RISE study participants had therefore had the opportunity to access facility-based care for 6 months before trial recruitment. There was some overlap between the studies as the PRIME study duration was 12 months.

RISE study participants included individuals who were participating in the PRIME study and individuals who had not participated in the PRIME study but had been identified by PRIME as having suspected 
schizophrenia (these participants had not attended facility-based care). Participants from the PRIME study were recruited at the PRIME 6-month data collection (or on a separate occasion if they did not attend) and individuals who were not participants in the PRIME study were recruited using the PRIME database of people with suspected schizophrenia. The initial contact for these patients was made by phone call or home visit by the data collector, and a full eligibility assessment visit was subsequently arranged.

For each participant, one primary caregiver was identified who met the criteria of being aged 18 years or older and providing regular support (eg, sustenance). Caregivers could be a spouse, relative, or friend. Potential participants were requested to attend data collection with a caregiver, who was screened for these criteria. If the original caregiver was unavailable at the 12 -month data collection, caregiver-reported data were collected from a different caregiver meeting the criteria.

Study participants with a schizophrenia diagnosis who were recruited during participation in the PRIME study underwent full RISE study eligibility assessment by the RISE trial nurse using data gathered at 6 months during the PRIME study. Study participants who were not from the PRIME study were assessed for eligibility, which included the diagnostic OPCRIT interview.

Participants were eligible to enrol in the study if they were aged 18 years or older; were a participant of the PRIME cohort study or residing in Sodo district but not engaged in facility-based care; had a diagnosis of schizophrenia, schizoaffective disorder, or schizophreniform disorder; had no intention to leave the subdistrict; had a primary caregiver willing to participate; and had one or more markers of severe, disabling, or enduring illness (Brief Psychiatric Rating Scale-Expanded [BPRSE] score $\geq 52$, proxy or self-rated 36-item WHO Disability Assessment Schedule [WHODAS] 2.0 score $\geq 35$, continuous illness lasting 6 months, symptomatic for $\geq 3$ of last 6 months, or Clinical Global Impression [CGI] severity score $\geq 3$ ).

Written informed consent was sought from each eligible participant and caregiver by a trial nurse. For those without capacity to consent, permission was sought from the caregiver and assent from the person with schizophrenia. Individuals were not recruited if they expressed unwillingness to participate. If the participant was unable to write, a thumb impression and a witness's signature were recorded.

\section{Randomisation and masking}

Randomisation of subdistricts was carried out before participant recruitment by an independent statistician. 54 subdistricts were randomised (in a 1:1 ratio) to either the intervention (CBR plus facility-based care group) or to the control group (facility-based care alone group). Cluster randomisation was chosen because CBR includes community-level elements.
To prevent an imbalance for potential confounding factors an independent statistician employed an optimisation algorithm calculated for subdistrict mean WHODAS score at PRIME baseline and the potential number of participants per subdistrict. Although not all patients had a PRIME baseline WHODAS score, the majority of participants did; therefore, we deemed that it was appropriate to use these scores to ensure balance between the treatment groups.

They applied the procedure for each of the eight health facilities and used a computer program to randomly choose the allocation sequence from the set of optimal ones. The statistician was masked to the intervention or control label. Researchers responsible for recruiting participants and collecting outcome data were masked to allocation status. To minimise unmasking, participants and CBR workers were requested not to divulge allocation status to researchers, data collectors were assigned to subdistricts where they had no personal links, and primary outcome data were collected first at each assessment. All coauthors (except RB) remained masked until the final analysis was complete.

\section{Procedures}

Facility-based care is a stepped care model. The majority of care was delivered in primary care, which comprised prescription of antipsychotic medication, and psychoeducation by nurses and health officers trained for 2 weeks in the WHO mental health Gap Action ProgrammeIntervention Guide (mhGAP) supervised by a psychiatric nurse. The frequency of contact was determined by clinical need, and there was no minimum requirement. Primary care staff could refer participants to psychiatric nurse-led outpatient care (secondary care) or psychiatristled inpatient care (tertiary care). Health extension workers in each subdistrict were trained in raising awareness of the causes and treatment of mental health disorders. A district-level community-advisory board oversaw implementation of the facility-based care model.

CBR was delivered by 11 CBR workers, each covering a catchment area of one, two, or three subdistricts linked to a health centre. CBR delivery lasted 12 months, commencing immediately after trial recruitment. CBR workers supported a median of seven participants (range 4-11). CBR workers were lay people recruited from the local area with at least 10 years of education but no previous mental health care experience. They received 5 weeks initial manualised training (approximately $150 \mathrm{~h}$ ) in CBR delivery, including basic counselling and problem-solving techniques, followed by monthly halfday additional training. ${ }^{14}$ Training was delivered by psychiatrists and CBR coordinators and was split between classroom teaching and fieldwork. In the pretrial pilot study CBR workers delivered CBR to one family for 6 months. ${ }^{10}$

CBR visits took place at the participants' home and lasted 30-90 mins. The intervention was recovery-oriented, 
rights-based and emphasised social inclusion. Topics included psychoeducation, adherence support, family intervention, crisis management, support returning to work and social activities, and dealing with stigma and stress. In phase 1 (2-3 months duration), home visits were every 1-2 weeks, and the focus was on engagement and addressing core needs. In phase 2 (5-6 months duration), home visits were every 2 weeks. A subset from 11 optional modules were selected to address individual goals. In phase 3 (approximately 4 months duration), the emphasis was on maintaining progress. CBR workers met with community members to mobilise resources for individual participants-eg, treatment costs, food, social support, or family mediation. CBR workers supported facility-based care engagement-eg, attempting to obtain medication fee waivers. At a subdistrict level, CBR workers conducted community mobilisation (eg, meetings raising public awareness and engaging with community leaders) and ran family support groups. Two supervisors, who were not mental health specialists, oversaw the frequency and content of home visits. In addition to regular appointments, CBR workers referred participants to the health centre if suicidal intent, relapse, or medication side-effects were identified.

Process data were recorded at the levels of participant (home visits and community mobilisation), subdistrict (community mobilisation and family group meetings), and CBR worker (Enhancing Assessment of Common Therapeutic Factors-Ethiopia [ENACTE] competency assessments, ${ }^{14}$ conducted by independent psychiatric nurses). Minimum adequate CBR participation was predefined as ten or more home visits and optimal CBR participation was predefined as 21 or more home visits.

Data were collected at baseline, 6 months, and 12 months (primary endpoint) at the participant's home or health centre. Sociodemographic information was collected at the PRIME cohort study baseline, or (for participants not in the PRIME cohort study) at RISE trial baseline. Self-rated WHODAS data was collected at PRIME baseline and used for the optimisation algorithm employed in randomisation. Self-reported prescription of antipsychotic medication (all timepoints) and receipt of free medication (12 months only) was recorded.

\section{Outcomes}

All outcomes were measured at an individual level. The primary outcome was disability, measured with the proxy-rated 36-item WHODAS 2.0 total score at 12 months (with a prespecified timeframe of 10 weeks either side of the 12 months), calculated using itemresponse theory-based scoring. Normative data indicate $95 \%$ of the general population score less than 50 (range 0-100)..$^{15}$ Domain scores for understanding and communication, getting around, self-care, getting along with people, life activities (household and work), and participation in society were secondary outcomes.
WHODAS 2.0 is an instrument for assessing disability relating to any health condition across cultures. Sociocultural adaptation and validation of the WHODAS in people with schizophrenia has been completed in Ethiopia. ${ }^{16}$ The rationale for using the proxy version, completed by a caregiver, was that reporting can vary among people with schizophrenia according to their mental state, and the proxy version showed a greater responsiveness to change in a local study. ${ }^{16}$

Secondary outcomes were 6-month proxy-rated WHODAS total and domain scores; 6 and 12-month symptom severity (CGI); ${ }^{17}$ and 12 -month self-rated WHODAS total and domain scores, proxy and selfrated days unable to work in the past month, symptom severity (BPRSE), ${ }^{18}$ Butajira Functioning Scale (BFS) score (a locally developed scale), ${ }^{19}$ relapse (Life Chart Schedule) ${ }^{20}$ health facility attendance for mental health (adapted Client Service Receipt Inventory [CSRI]), medication non-adherence (ordinal and 4-item Morisky Medication Adherence scales), physical restraint, discrimination (Discrimination and Stigma Scale-12), ${ }^{21}$ and employment. Caregiver outcomes were caregiving burden (Involvement Evaluation Questionnaire [IEQ]) and mood (Patient Health Questionnaire-9 [PHQ-9]), ${ }^{22}$ shown in the appendix (pp 2-3). We systematically assessed for the serious adverse events: death (by suicide or any cause), suicide attempts, and hospital admissions (due to suicide attempt, serious side effect of anti-psychotic medication, or any other serious medical emergency). We also recorded any other adverse events that were detected. Lay data collectors collected all data except for symptom severity, relapse, and prescription of medication, which were collected by psychiatric nurses.

\section{Statistical analysis}

Assuming a 23\% attrition rate, we aimed to recruit 182 participants to provide a sample size for analysis of 140 participants with schizophrenia in 54 subdistricts. This sample size provides $85 \%$ power to detect a $20 \%$ absolute difference in WHODAS scores between the treatment groups, with 5\% significance, assuming a mean WHODAS score of 50 in the control (facility-based care) group, a co-efficient of variation of $0 \cdot 14$, and a within-cluster SD of 16 .

Initial analyses compared the baseline characteristics of participants and subdistricts with the completion of 12-month outcome assessments and between treatment groups. Analyses were done in participants according to the group that they were randomised to. Outcome measures were summarised at baseline, 6-month, and 12 -month data points by treatment group. For continuous outcomes, we estimated intervention effects using linear mixed-effects regression and reported them as minimally-adjusted mean differences, fully-adjusted mean differences (FAMDs), and effect sizes defined as standardised mean differences, with $95 \%$ CIs. For binary 


\begin{tabular}{|c|c|c|}
\hline & $\begin{array}{l}\text { Facility- } \\
\text { based care } \\
\text { group } \\
(n=87)\end{array}$ & $\begin{array}{l}\text { CBR plus } \\
\text { facility-based } \\
\text { care group } \\
(n=79)\end{array}$ \\
\hline \multicolumn{3}{|l|}{ Participant } \\
\hline \multicolumn{3}{|l|}{ Sex } \\
\hline Male & $51(59 \%)$ & $52(66 \%)$ \\
\hline Female & $36(41 \%)$ & $27(34 \%)$ \\
\hline Age, years (median [IQR]) & $33(25-40)$ & $30(25-45)$ \\
\hline \multicolumn{3}{|l|}{ Marital status* } \\
\hline Single & $41 / 80(51 \%)$ & $38 / 75(51 \%)$ \\
\hline $\begin{array}{l}\text { Has a partner (married or married but } \\
\text { not living together) }\end{array}$ & $26 / 80(33 \%)$ & $25 / 75(33 \%)$ \\
\hline Separated, divorced, or widowed & $13 / 80(16 \%)$ & $12 / 75(16 \%)$ \\
\hline \multicolumn{3}{|l|}{ Occupation } \\
\hline No occupation & $15(17 \%)$ & $9(11 \%)$ \\
\hline Home worker & $33(38 \%)$ & $27(34 \%)$ \\
\hline Unskilled labourer & $34(39 \%)$ & $42(53 \%)$ \\
\hline Other & $5(6 \%)$ & $1(1 \%)$ \\
\hline \multicolumn{3}{|l|}{ Education status* } \\
\hline No formal education & $46 / 80(58 \%)$ & $36 / 75(48 \%)$ \\
\hline Primary education & $22 / 80(28 \%)$ & $35 / 75(47 \%)$ \\
\hline Secondary education and above & $12 / 80(15 \%)$ & $4 / 75(5 \%)$ \\
\hline \multicolumn{3}{|l|}{ Socioeconomic status* } \\
\hline Higher (poverty index $\leq 3$ ) & $42 / 80(53 \%)$ & $47 / 74(64 \%)$ \\
\hline Lower (poverty index >3) & $38 / 80(48 \%)$ & $27 / 74(36 \%)$ \\
\hline \multicolumn{3}{|l|}{ Residence* } \\
\hline Urban & $11 / 80(14 \%)$ & 8/74 (11\%) \\
\hline Rural & $69 / 80(86 \%)$ & $66 / 74(89 \%)$ \\
\hline \multicolumn{3}{|l|}{ Travel time to nearest health facility* } \\
\hline$\leq 60$ mins & $51 / 80(64 \%)$ & $48 / 75(64 \%)$ \\
\hline $61-120$ mins & $13 / 80(16 \%)$ & $17 / 75(23 \%)$ \\
\hline$\geq 121$ mins & $16 / 80(20 \%)$ & $10 / 75(13 \%)$ \\
\hline \multicolumn{3}{|l|}{ Diagnosis } \\
\hline Schizophrenia & $70(80 \%)$ & $68(86 \%)$ \\
\hline $\begin{array}{l}\text { Schizoaffective or schizophreniform } \\
\text { disorder }\end{array}$ & $17(20 \%)$ & $11(14 \%)$ \\
\hline $\begin{array}{l}\text { Duration of illness in years* (median } \\
{[\mathrm{IQR}] \text { ) }}\end{array}$ & $\begin{array}{l}4(1 \cdot 9-9) \\
\mathrm{n}=64\end{array}$ & $\begin{aligned} & 3 \cdot 7(1 \cdot 5-7 \cdot 3) ; \\
\mathrm{n} & =55\end{aligned}$ \\
\hline \multicolumn{3}{|l|}{ Comorbid medical disorder* } \\
\hline No & $69 / 76(91 \%)$ & $69 / 72(96 \%)$ \\
\hline Yes & $7 / 76(9 \%)$ & $3 / 72(4 \%)$ \\
\hline Proxy-rated total WHODAS (mean [SD]) & $52 \cdot 6(23 \cdot 6)$ & $50 \cdot 2(23 \cdot 6)$ \\
\hline BPRSE total (mean [SD]) & $\begin{array}{l}47 \cdot 2(13 \cdot 4) \\
\mathrm{n}=85\end{array}$ & $\begin{array}{l}48 \cdot 9(14 \cdot 2) ; \\
n=75\end{array}$ \\
\hline \multicolumn{3}{|l|}{ CGI } \\
\hline Normal or borderline score & $6(7 \%)$ & $2(3 \%)$ \\
\hline At least mildly ill (score $\geq 3$ ) & $81(93 \%)$ & $77(97 \%)$ \\
\hline
\end{tabular}

\begin{tabular}{|c|c|c|}
\hline & $\begin{array}{l}\text { Facility- } \\
\text { based care } \\
\text { group } \\
(n=87)\end{array}$ & $\begin{array}{l}\text { CBR plus } \\
\text { facility-based } \\
\text { care group } \\
(n=79)\end{array}$ \\
\hline \multicolumn{3}{|l|}{ (Continued from previous column) } \\
\hline \multicolumn{3}{|l|}{ Illness course lasting 6 months (LCS) } \\
\hline Episodic & $3(3 \%)$ & $4(5 \%)$ \\
\hline Continuous & $66(76 \%)$ & $66(84 \%)$ \\
\hline Never psychotic & $18(21 \%)$ & $9(11 \%)$ \\
\hline \multicolumn{3}{|l|}{ Antipsychotic medication adherence } \\
\hline All or most of the time & $35 / 83(42 \%)$ & $36 / 77(47 \%)$ \\
\hline Sometimes, occasionally, or not at all & $48 / 83(58 \%)$ & $41 / 77(53 \%)$ \\
\hline \multicolumn{3}{|l|}{ Engagement with care } \\
\hline $\begin{array}{l}\text { No healthcare attendance and no } \\
\text { medication adherence }\end{array}$ & $32 / 83(39 \%)$ & $30 / 77(39 \%)$ \\
\hline $\begin{array}{l}\text { Either healthcare attendance or } \\
\text { medication adherence }\end{array}$ & $23 / 83(28 \%)$ & $17 / 77(22 \%)$ \\
\hline $\begin{array}{l}\text { Healthcare attendance and medication } \\
\text { adherence }\end{array}$ & $28 / 83(34 \%)$ & $30 / 77(39 \%)$ \\
\hline \multicolumn{3}{|l|}{ AUDIT total $\geq 8$} \\
\hline No & $70 / 86(81 \%)$ & $58 / 74(78 \%)$ \\
\hline Yes & $16 / 86(19 \%)$ & $16 / 74(22 \%)$ \\
\hline \multicolumn{3}{|l|}{ Restrained last 6 months } \\
\hline No & $82(94 \%)$ & $75(95 \%)$ \\
\hline Yes & $5(6 \%)$ & $4(5 \%)$ \\
\hline \multicolumn{3}{|c|}{ Any experience of discrimination last 6 months } \\
\hline No & $40(46 \%)$ & $38(48 \%)$ \\
\hline Yes & $47(54 \%)$ & $41(52 \%)$ \\
\hline \multicolumn{3}{|l|}{ Unemployed } \\
\hline No & $32(37 \%)$ & $38(48 \%)$ \\
\hline Yes & $55(63 \%)$ & $41(52 \%)$ \\
\hline \multicolumn{3}{|l|}{ Social support } \\
\hline Poor & $23(26 \%)$ & $35(44 \%)$ \\
\hline Intermediate & $49(56 \%)$ & $31(39 \%)$ \\
\hline Strong & $15(17 \%)$ & $13(17 \%)$ \\
\hline \multicolumn{3}{|l|}{ Caregiver } \\
\hline Mean total IEQ score (mean [SD]) & $40 \cdot 1(16 \cdot 0)$ & $40 \cdot 7(19 \cdot 4)$ \\
\hline \multicolumn{3}{|l|}{ PHQ- 9 score $\geq 5$} \\
\hline No & $57(66 \%)$ & $36(46 \%)$ \\
\hline Yes & $30(34 \%)$ & $43(54 \%)$ \\
\hline \multicolumn{3}{|l|}{ Unemployed } \\
\hline No & $55(63 \%)$ & $43(54 \%)$ \\
\hline \multirow[t]{2}{*}{ Yes } & $32(37 \%)$ & $36(46 \%)$ \\
\hline & \multicolumn{2}{|c|}{ (Table 1 continues in next column) } \\
\hline
\end{tabular}

outcomes, we reported intervention effects as minimally-adjusted, fully-adjusted odds ratios (FAORs), and 95\% CIs estimated from logistic random effect regression models. Minimally-adjusted models included baseline proxy-rated WHODAS total score, health centre (fixed effect), and subdistrict (random effect). Fully adjusted models included variables associated with 


\begin{tabular}{|c|c|c|}
\hline & $\begin{array}{l}\text { Facility- } \\
\text { based care } \\
\text { group } \\
(n=87)\end{array}$ & $\begin{array}{l}\text { CBR plus } \\
\text { facility-based } \\
\text { care group } \\
(n=79)\end{array}$ \\
\hline \multicolumn{3}{|l|}{ (Continued from previous column) } \\
\hline \multicolumn{3}{|l|}{ Sub-district } \\
\hline \multicolumn{3}{|l|}{ Location } \\
\hline Urban & $1 / 24(4 \%)$ & $2 / 24(8 \%)$ \\
\hline Rural & $23 / 24(96 \%)$ & $22 / 24(92 \%)$ \\
\hline $\begin{array}{l}\text { Baseline number of participants } \\
\text { (median [IQR]) }\end{array}$ & $3(1.5-4 \cdot 5)$ & $2 \cdot 5(1-5)$ \\
\hline $\begin{array}{l}\text { Proxy-rated total WHODAS (median } \\
\text { [IQR]) }\end{array}$ & $\begin{array}{l}52 \cdot 8 \\
(45 \cdot 2-61 \cdot 1)\end{array}$ & $\begin{array}{l}54 \cdot 1 \\
(41 \cdot 4-62 \cdot 4)\end{array}$ \\
\hline \multicolumn{3}{|c|}{$\begin{array}{l}\text { Data are nor } n / \mathrm{N}(\%) \text { unless otherwise indicated. Percentage totals might not } \\
\text { equal } 100 \% \text { due to rounding. CBR=community-based rehabilitation. } \\
\text { WHODAS=World Health Organization Disability Assessment Schedule. } \\
\text { BPRSE=Brief Psychiatric Rating Scale Expanded. CGI=Clinical Global Impression } \\
\text { scale. LCS=Life Chart Schedule. AUDIT=Alcohol Use Disorder Identification Test. } \\
\text { IEQ=Involvement Evaluation Questionnaire. PHQ-9=Patient Health } \\
\text { Questionairre-9. *Data collected at PRIME cohort study baseline. }\end{array}$} \\
\hline
\end{tabular}

missingness (threshold $\mathrm{p}<0 \cdot 10$ ), and variables deemed unbalanced between groups at baseline.

We assessed modification of treatment effect by predefined effect modifiers (sex and baseline symptom severity, disability, alcohol use disorder, social support, and socioeconomic status) using the likelihood ratio test. If two or less WHODAS items were missing, the mean score across all domain items was assigned to the missing items.

Process data were summarised for participant, subdistrict, and CBR worker levels. We calculated the proportion of participants prescribed antipsychotic medication at each timepoint and accessing free medication at 12 months; the numbers and proportions of participants lost to follow-up, and the reasons overall and by group; the proportion of participants for whom the assessor was unmasked; and the numbers and proportions of participants with each serious adverse event type and any serious adverse event by group.

The primary analyses were complete case (ie, we only included participants with data on the variables of interest). Sensitivity analyses included inclusion of participants with data collected within the timeframe of 6 weeks either side of the 12 months or at any time; exclusion of caregivers who differed between baseline and 12 months; and multiple imputation of missing data with a linear or logistic imputation model as appropriate, adjusting for factors associated with missingness, for the imputation with 50 imputed datasets. Statistical analyses were done with Stata, version 15. All analyses were prespecified, except the description of medication prescription. An independent Data Safety and Monitoring Board oversaw the study. The trial is registered with ClinicalTrials.gov, NCT02160249.

\section{Role of the funding source}

The funder of the study had no role in study design, data collection, data analysis, data interpretation, or writing of the report.

\section{Results}

Participants were enrolled between Sept 16, 2015, and March 11, 2016, (figure). Of the 54 available subdistricts, 27 were randomly assigned to the CBR plus facility-based care group and 27 to the facility-based care group. A total of 294 potential participants were prescreened and 91 were excluded. A further 37 individuals were not enrolled; of these, one participant and six $(3 \%)$ caregivers of 203 participants and linked caregivers declined (three caregivers in the CBR plus facility-based care group and one participant and three caregivers in the facility-based care group). Three subdistricts were excluded at each of the prescreening and enrolment stages because there were no eligible participants. Therefore, 48 of 54 potential subdistricts were included. 24 subdistricts (79 participants) were assigned to the CBR plus facility-based care group and 24 subdistricts (87 participants) were assigned to the facility-based care group. Primary outcome data collected in the predefined timeframe were available for 73 (92\%) of 79 participants in the CBR plus facility-based care group (22 subdistricts) and $76(87 \%)$ of 87 participants in the facility-based care group (24 subdistricts); see figure).

Participants had a median age of 31.4 years (range 18.0-80.0). At baseline there were high levels of disability (mean proxy-rated WHODAS $51 \cdot 5$ [SD 23.6]), and 132 (80\%) of 166 participants reported continuous illness over the previous 6 months. Participants in the facility-based care group were more likely than those in the CBR plus facility-based care group to be female, to have lower household socio-economic status, to be unemployed, and to have social support. Caregivers in the facility-based care group were less likely to be unemployed or be depressed than caregivers in the CBR plus facility-based care group (table 1). At baseline, $38(44 \%)$ of 87 participants in the facility-based care group and 42 (54\%) of 79 participants in the CBR plus facility-based care group had been prescribed antipsychotic medication, increasing to 39 (49\%) of 79 participants in the facility-based care group and 58 (77\%) of 75 participants in the CBR plus facility-based care group at 12-months (appendix p 3). Almost all prescriptions were for oral first-generation antipsychotics (chlorpromazine and haloperidol). At 12-months, free antipsychotic medication was available to $24(30 \%)$ of 79 participants in the facility-based care group and 37 (50\%) of 74 participants in the CBR plus facility-based care group (appendix p 3).

There was evidence of a favourable intervention effect on the primary outcome, proxy-rated WHODAS score at 12 months. The mean WHODAS scores at 12 months were $46 \cdot 1$ (SD 23.3) in the facility-based care group and 


\begin{tabular}{|c|c|c|c|c|c|c|c|}
\hline & \multirow{2}{*}{$\begin{array}{l}\text { Facility-based care } \\
(n=76)\end{array}$} & \multirow{2}{*}{$\begin{array}{l}\text { CBR plus facility- } \\
\text { based care }(n=73)\end{array}$} & \multicolumn{2}{|c|}{ Minimally adjusted analysis } & \multicolumn{2}{|l|}{ Fully adjusted analysis } & \multirow[t]{2}{*}{ Effect size $(95 \% \mathrm{Cl})$} \\
\hline & & & $\begin{array}{l}\text { Mean difference or odds } \\
\text { ratio }(95 \% \mathrm{Cl})^{*}\end{array}$ & $\mathrm{p}$ value & $\begin{array}{l}\text { Mean difference or odds } \\
\text { ratio }(95 \% \mathrm{Cl}) \dagger\end{array}$ & p value & \\
\hline \multicolumn{8}{|l|}{ Primary outcome } \\
\hline Proxy-rated WHODAS-36 total score & $46 \cdot 1(23 \cdot 3)$ & $40 \cdot 6(22 \cdot 5)$ & $-6 \cdot 23(-13 \cdot 82$ to $1 \cdot 35)$ & $0 \cdot 11$ & $-8 \cdot 13(-15 \cdot 85$ to $-0 \cdot 40)$ & 0.039 & $0.35(0.02$ to 0.67$)$ \\
\hline \multicolumn{8}{|l|}{ Secondary outcomes } \\
\hline \multicolumn{8}{|l|}{ Proxy-rated WHODAS-36 domain scores } \\
\hline Cognition & $53.9(29 \cdot 9)$ & $47 \cdot 1(30 \cdot 3)$ & $-5.97(-14.75$ to $2 \cdot 81)$ & 0.18 & $-9.65(19.31$ to 0.01$)$ & 0.050 & $0.32(-0.01$ to 0.64$)$ \\
\hline Mobility & $21 \cdot 5(24 \cdot 4)$ & $19 \cdot 4(21 \cdot 3)$ & $-2 \cdot 76(-12 \cdot 02$ to $6 \cdot 49)$ & 0.56 & $-3.07(-13 \cdot 52$ to $7 \cdot 38)$ & 0.57 & $0.13(-0.19$ to 0.46$)$ \\
\hline Self care & $32 \cdot 8(29 \cdot 0)$ & $30 \cdot 8(24 \cdot 3)$ & $-2 \cdot 48(-13 \cdot 34$ to $8 \cdot 38)$ & 0.65 & $-3 \cdot 44(-14 \cdot 4$ to $7 \cdot 56)$ & 0.54 & $0.13(-0.19$ to 0.45$)$ \\
\hline Getting along & $49 \cdot 3(31 \cdot 1)$ & $38.8(30 \cdot 9)$ & $-12 \cdot 20(-22 \cdot 38$ to $-2 \cdot 03)$ & 0.019 & $-14 \cdot 32(-26 \cdot 60$ to $-2 \cdot 05)$ & 0.022 & $0.45(0.12-0.77)$ \\
\hline Life activities: household & $66.6(33 \cdot 4)$ & $61 \cdot 1(34 \cdot 8)$ & $-6.09(-16.85$ to 4.67$)$ & 0.27 & $-7 \cdot 37(-18 \cdot 72$ to $3 \cdot 98)$ & $0 \cdot 20$ & $0.22(-0.11$ to 0.54$)$ \\
\hline Life activities: work & $62 \cdot 7(32 \cdot 0)$ & $56 \cdot 4(32 \cdot 6)$ & $-6 \cdot 51(-16 \cdot 49$ to $3 \cdot 47)$ & $0 \cdot 20$ & $-9.22(-20 \cdot 00$ to 1.57$)$ & 0.094 & $0.28(-0.04$ to 0.60$)$ \\
\hline Participation & $41 \cdot 7(23 \cdot 1)$ & $36 \cdot 5(24 \cdot 5)$ & $-6 \cdot 73(-14 \cdot 7$ to $1 \cdot 19)$ & 0.096 & $-8.86(-16.81$ to -0.91$)$ & 0.029 & 0.36 (0.04 to 0.69$)$ \\
\hline $\begin{array}{l}\text { Proxy-rated number of days unable to } \\
\text { work last month }\end{array}$ & $8(2 \cdot 5$ to 20$)$ & $7(3-15)$ & $-2 \cdot 64(-6 \cdot 22$ to $0 \cdot 95)$ & $0 \cdot 15$ & $-3 \cdot 04(-7 \cdot 10$ to $1 \cdot 03)$ & $0 \cdot 14$ & $0.30(-0.03$ to 0.62$)$ \\
\hline Self-rated WHODAS total score & $34 \cdot 2(24 \cdot 2) ; n=57$ & $29 \cdot 8(19 \cdot 8) ; n=59$ & $-3.65(-11.84$ to 4.54$)$ & $0 \cdot 38$ & $-4 \cdot 77(-13 \cdot 81$ to $4 \cdot 26)$ & $0 \cdot 30$ & $0.21(-0.15$ to 0.58$)$ \\
\hline \multicolumn{8}{|l|}{ Self-rated WHODAS domain scores } \\
\hline Cognition & $35 \cdot 3(29 \cdot 9) ; n=57$ & $32 \cdot 8(26 \cdot 9) ; n=59$ & $0.83(-10 \cdot 11$ to $11 \cdot 76)$ & 0.88 & $-2 \cdot 07(-14 \cdot 15$ to $10 \cdot 00)$ & 0.74 & $0.07(-0.29$ to 0.44$)$ \\
\hline Mobility & $15 \cdot 0(21 \cdot 3) ; n=57$ & $17 \cdot 8(21 \cdot 6) ; \mathrm{n}=59$ & $0 \cdot 59(-9 \cdot 30$ to $10 \cdot 48)$ & 0.91 & $2 \cdot 53(-7 \cdot 39$ to $12 \cdot 45)$ & 0.62 & $0.12(-0.25$ to 0.48$)$ \\
\hline Self-care & $21 \cdot 2(24 \cdot 1) ; n=57$ & $19 \cdot 5(18 \cdot 3) ; n=59$ & $-0.83(-10 \cdot 26$ to $8 \cdot 60)$ & 0.86 & $-1 \cdot 16(-10 \cdot 22$ to $7 \cdot 90)$ & 0.80 & $0.05(-0.31$ to 0.42$)$ \\
\hline Getting along & $34 \cdot 4(32 \cdot 0) ; n=57$ & $25 \cdot 0(24 \cdot 5) ; n=59$ & $-6.82(-17.59$ to 3.95$)$ & 0.22 & $-7 \cdot 76(-19 \cdot 60$ to 4.08$)$ & $0 \cdot 20$ & $0.27(-0.10$ to 0.63$)$ \\
\hline Life activities: household & $55 \cdot 6(36 \cdot 4) ; n=57$ & $47 \cdot 5(34 \cdot 4) ; n=59$ & $-7 \cdot 19(-19 \cdot 85$ to $5 \cdot 47)$ & $0 \cdot 27$ & $-11.96(-25.92$ to 1.99$)$ & 0.093 & $0.33(-0.03$ to 0.70$)$ \\
\hline Life activities: work & $50 \cdot 3(33 \cdot 5) ; n=57$ & $42 \cdot 7(33 \cdot 0) ; n=59$ & $-7 \cdot 24(-18 \cdot 95$ to $4 \cdot 47)$ & 0.23 & $-10 \cdot 05(-22.95$ to $2 \cdot 85)$ & $0 \cdot 13$ & $0.30(-0.07$ to 0.66$)$ \\
\hline Participation & $33.0(23.7) ; n=57$ & $27 \cdot 0(21 \cdot 2) ; n=59$ & $-5 \cdot 84(-14 \cdot 33$ to $2 \cdot 64)$ & $0 \cdot 18$ & $-5 \cdot 70(-15 \cdot 82$ to $4 \cdot 41)$ & $0 \cdot 27$ & $0.25(-0.11$ to 0.62$)$ \\
\hline $\begin{array}{l}\text { Self-rated number of days unable work last } \\
\text { month }\end{array}$ & $4(0$ to 10$) ; n=57$ & $5(0$ to 10$) ; n=59$ & $-1 \cdot 92(-5 \cdot 19$ to $1 \cdot 35)$ & $0 \cdot 25$ & $-2 \cdot 06(-5 \cdot 35$ to $1 \cdot 23)$ & $0 \cdot 22$ & $0.27(-0.10$ to 0.63$)$ \\
\hline Proxy-rated Butajira Functioning Scale & $98 \cdot 5(38 \cdot 7)$ & $88 \cdot 4(35 \cdot 8)$ & $-7 \cdot 15(-20 \cdot 11$ to $5 \cdot 81)$ & $0 \cdot 28$ & $-5 \cdot 39(-18 \cdot 96$ to $8 \cdot 18)$ & $0 \cdot 44$ & $0.14(-0.18$ to 0.46$)$ \\
\hline \multicolumn{8}{|l|}{ Symptom severity } \\
\hline BPRSE score $\ddagger$ & $45 \cdot 4(13 \cdot 7) ; n=68$ & $41 \cdot 6(15 \cdot 6) ; n=67$ & $-4 \cdot 81(-10 \cdot 08$ to $0 \cdot 47)$ & 0.074 & $-5 \cdot 31(-10 \cdot 86$ to $0 \cdot 23)$ & 0.060 & $0.36(-0.01$ to 0.70$)$ \\
\hline At least mildly ill (CGI score $\geq 3$ ) $\ddagger$ & $63(83 \%)$ & $48(66 \%)$ & OR 0.37 ( 0.16 to 0.85$)$ & 0.020 & OR $0.26(0.09$ to 0.81$) \S$ & 0.019 & .. \\
\hline \multicolumn{8}{|l|}{ Relapse } \\
\hline Relapsed & $15(21 \%) ; n=73$ & $17(25 \%) ; n=67$ & OR 1.06 (0.38 to 2.97$)$ & 0.91 & OR 1.46 (0.46 to 4.64$) \boldsymbol{\top}$ & 0.52 & .. \\
\hline \multicolumn{8}{|l|}{ Medication \& health service use } \\
\hline $\begin{array}{l}\text { Non-adherent (takes medication } \\
\text { sometimes, occasionally, or never) }\end{array}$ & $43(57 \%)$ & $21(29 \%)$ & OR $0.16(0.05$ to 0.51$)$ & 0.0020 & OR 0.19 (0.07 to 0.51$)$ & 0.0010 & .. \\
\hline Any non-adherent behaviour & $46(61 \%)$ & $34(47 \%)$ & OR $0.50(0.24$ to 1.07$)$ & 0.08 & OR $0.63(0.25$ to 1.56$)$ & $0 \cdot 32$ &. \\
\hline $\begin{array}{l}\text { No attendance at a health facility for } \\
\text { mental health in the last } 3 \text { months }\end{array}$ & $36(47 \%)$ & $15(21 \%)$ & OR 0.23 (0.10 to 0.54$)$ & 0.0010 & OR 0.19 (0.07 to 0.54$)$ & 0.0020 &. \\
\hline \multicolumn{8}{|l|}{ Physical restraint } \\
\hline Restrained in the last 6 months & $5(7 \%)$ & $5(7 \%)$ & OR 1.09 ( 0.23 to 5.15$)$ & 0.91 & OR 2.72 (0.34 to 21.83$) \boldsymbol{\top}$ & $0 \cdot 35$ &. \\
\hline \multicolumn{8}{|l|}{ Discrimination } \\
\hline $\begin{array}{l}\text { Any experience of discrimination in the } \\
\text { last } 6 \text { months }\end{array}$ & $39(51 \%)$ & $46(63 \%)$ & OR 2.08 (0.98 to 4.42$)$ & 0.057 & OR 2.26 ( 0.88 to $5 \cdot 81)$ & 0.089 &. \\
\hline \multicolumn{8}{|l|}{ Economic activity } \\
\hline Unemployed & $47(62 \%)$ & $51(70 \%)$ & OR 1.76 (0.69 to 4.49$)$ & 0.24 & OR 3.80 (1.10 to 13.07$)$ & 0.034 & .. \\
\hline $\begin{array}{l}\text { Data are } n(\%) \text {, mean (SD), or median (IQR) unle } \\
\text { WHODAS= World Health Organization Disability } \\
\text { PHQ-9=Patient Health Questionnaire- } 9 \text {. *Adjust } \\
\text { (cluster) as a random effect and health centre, b } \\
\text { caregiver burden (IEQ), illness duration, baseline } \\
\text { social support reduced to two categories to avoi } \\
\text { SFully adjusted model excludes residence due to }\end{array}$ & $\begin{array}{l}\text { Assessment Schedule. B } \\
\text { ed for sub-district (clust } \\
\text { aseline score of outcome } \\
\text { employment status, bas } \\
\text { d problems with data sp. } \\
\text { data sparsity. } \text { ๆFully adj }\end{array}$ & $\begin{array}{l}\text { ontinuous outcomes dis } \\
\text { PRSE=Brief Psychiatric } \\
\text { er) as random effect anc } \\
\text {, baseline disability (pro } \\
\text { eline caregiver employr } \\
\text { arsity. \#For BPRSE and C } \\
\text { נsted model excludes so }\end{array}$ & $\begin{array}{l}\text { y adjusted mean difference } \\
\text { alth centre and baseline scc } \\
\text { rated total WHODAS), sex, } \\
\text { t status, baseline social sup } \\
\text { clinician administered inter } \\
\text { economic status due to dat }\end{array}$ & $\begin{array}{l}\text { of outcom } \\
\text {, residence, } \\
\text { rt, and bas } \\
\text { parsity. }\end{array}$ & $\begin{array}{l}\text { comes display odds ratio. C } \\
\text { ression scale. IEQ=Involvem } \\
\text { as fixed effects. †Unless oth } \\
\text { aseline socio-economic sta } \\
\text { ne caregiver depression (PH } \\
\text { ipant differs to all other out }\end{array}$ & $\begin{array}{l}\text { ise state } \\
\text { baseline } \\
\text { mes (lixe } \\
\text { mes (lay }\end{array}$ & $\begin{array}{l}\text {-based rehabilitation. } \\
\text { Questionnaire. } \\
\text { djusted for sub-district } \\
\text { ness course, baseline } \\
\text { ffects. Illness course and } \\
\text { a collector interview). }\end{array}$ \\
\hline
\end{tabular}




\begin{tabular}{|c|c|c|c|c|c|c|c|}
\hline & \multirow{2}{*}{$\begin{array}{l}\text { Facility-based } \\
\text { care }(n=76)\end{array}$} & \multirow{2}{*}{$\begin{array}{l}\text { CBR plus } \\
\text { facility-based } \\
\text { care }(n=73)\end{array}$} & \multicolumn{2}{|c|}{ Minimally adjusted analysis } & \multicolumn{2}{|l|}{ Fully adjusted analysis } & \multirow[t]{2}{*}{ Effect size (95\% Cl) } \\
\hline & & & $\begin{array}{l}\text { Mean difference or } \\
\text { odds ratio }(95 \% \mathrm{Cl})^{*}\end{array}$ & $p$ value & $\begin{array}{l}\text { Mean difference or } \\
\text { odds ratio }(95 \% \mathrm{Cl}) \dagger\end{array}$ & $\mathrm{p}$ value & \\
\hline \multicolumn{8}{|l|}{ Caregiver depression } \\
\hline PHQ-9 score & $4 \cdot 9(3 \cdot 3)$ & $4 \cdot 8(3 \cdot 2)$ & $-0.66(-2.05$ to 0.73$)$ & 0.35 & $-0.52(-1.72$ to 0.69$)$ & 0.40 & $0.16(-0.16$ to 0.48$)$ \\
\hline PHQ-9 score $\geq 5$ & $35(46 \%)$ & $38(52 \%)$ & OR 0.88 ( 0.34 to 2.28 ) & 0.79 & OR 0.94 (0.32 to 2.81$)$ & 0.91 &.. \\
\hline \multicolumn{8}{|c|}{ Caregiver caring burden } \\
\hline IEQ urging domain & $12 \cdot 1(6 \cdot 1)$ & $14 \cdot 1(6 \cdot 4)$ & $2 \cdot 23$ (-0.33 to 4.79$)$ & 0.088 & $1.44(-0.88$ to 3.77$)$ & 0.22 & 0.23 (-0.55 to 0.09$)$ \\
\hline $\begin{array}{l}\text { IEQ supervision } \\
\text { domain }\end{array}$ & $6 \cdot 4(5 \cdot 2)$ & $7 \cdot 2(5 \cdot 3)$ & $0.92(-0.92$ to 2.76$)$ & 0.33 & $0.29(-1.74$ to $2 \cdot 33)$ & 0.78 & $0.06(-0.38$ to 0.27$)$ \\
\hline IEQ tension domain & $6 \cdot 6(5 \cdot 1)$ & $5 \cdot 6(5 \cdot 5)$ & $-1.59(-3.20$ to 0.02$)$ & 0.053 & $-1.83(-3.62$ to -0.05$)$ & 0.044 & $0.34(0.02$ to 0.66$)$ \\
\hline IEQ worrying domain & $10 \cdot 3(6 \cdot 2)$ & $9 \cdot 5(6 \cdot 6)$ & $-1.18(-3.51$ to 1.15$)$ & 0.32 & $-2 \cdot 17(-4 \cdot 26$ to -0.08$)$ & 0.042 & 0.34 (0.01 to 0.66$)$ \\
\hline $\begin{array}{l}\text { Reduced work due to } \\
\text { caring }\end{array}$ & $25(33 \%)$ & $23(32 \%)$ & OR 0.94 (0.39 to 2.23 ) & 0.88 & OR 0.92 (0.35 to 2.44$)$ & 0.87 &.. \\
\hline \multicolumn{8}{|c|}{$\begin{array}{l}\text { Data are n (\%) or mean (SD) unless otherwise indicated. Continuous outcomes display adjusted mean differences and binary outcomes display odds ratio. PHQ-9=Patient } \\
\text { Health Questionairre-9. IEQ=Involvement Education Questionnaire. *Adjusted for subdistrict (cluster) as random effect and health centre and baseline score of outcome as } \\
\text { fixed effects. †Adjusted for subdistrict (cluster) as a random effect and health centre, baseline score of outcome, baseline disability (proxy-rated total WHODAS), sex, age, } \\
\text { residence, baseline socio-economic status, baseline illness course, baseline caregiver burden (IEQ), illness duration, baseline employment status, baseline caregiver } \\
\text { employment status, baseline social support, and baseline caregiver depression (PHQ-9) as fixed effects. Illness course and social support reduced to two categories to avoid } \\
\text { problems with data sparsity. }\end{array}$} \\
\hline
\end{tabular}

$40.6(22.5)$ in the CBR plus facility-based care group (FAMD $-8 \cdot 13$ [95\% CI $-15 \cdot 85$ to $-0 \cdot 40]$; $\mathrm{p}=0 \cdot 039$; effect size $=0 \cdot 35$; table 2 ). There were also favourable effects on the secondary outcomes of proxy-rated WHODAS domain scores of cognition (FAMD -9.65 [95\% CI -19.31 to 0.01]; $\mathrm{p}=0 \cdot 050$ ), getting along (FAMD $-14 \cdot 32[-26 \cdot 60$ to $-2 \cdot 05]$; $\mathrm{p}=0.022$ ), participation (FAMD $-8.86[-16.81$ to -0.91$]$; $\mathrm{p}=0 \cdot 029)$, and illness severity measured with the CGI (FAOR $0 \cdot 26$ [95\% CI 0.09-0.81]; $\mathrm{p}=0 \cdot 019$ ). The FAMD on the BPRSE score was -5.31 (95\% CI -10.86 to 0.23 ; $\mathrm{p}=0 \cdot 060)$. There was no evidence of intervention effects on discrimination (FAOR 2.26 [95\% CI 0 88-5 -81]; $\mathrm{p}=0 \cdot 089$ ), restraint (FAOR 2.72 [0.34-21.83]; $\mathrm{p}=0.35$ ), or the WHODAS domains of work (FAMD -9.22 [95\% CI -20.00 to 1.57$] ; \mathrm{p}=0.094)$, household (FAMD -7.37 [-18.72 to 3.98]; $\mathrm{p}=0 \cdot 20$ ) and self-care (FAMD -3.44 [-14.4 to 7.56$] ; \mathrm{p}=0.54$ ) at 12 months (table 2); or WHODAS total score or illness severity at 6 months (appendix p 4). Participants in the CBR plus facility-based care group were less likely to have no attendance to a health facility for mental health in the past 3 months than participants in the facility-based care group (FAOR 0.19 [95\% CI 0.07-0 - 54]; $\mathrm{p}=0 \cdot 0020$ ), and they were less likely to report poor frequency of adherence to antipsychotic medication (FAOR 0.19 [95\% CI 0.07-0.51]; $\mathrm{p}=0 \cdot 0010$ ). However, no effect was observed on adherence behaviours measured with the Morisky Scale (FAOR 0.63 [95\% CI $0 \cdot 25-1 \cdot 56] ; p=0 \cdot 32)$. Participants in the CBR plus facilitybased care group were more likely to be unemployed compared to participants in the facility-based care group (FAOR 3.80 [95\% CI 1.10-13.07; $\mathrm{p}=0 \cdot 034$ ). There were beneficial intervention effects on caregiver burden in the
IEQ domains of tension (FAMD $-1.83 \quad[95 \%$ CI -3.62 to -0.05$] ; \mathrm{p}=0.044$ ) and worrying (FAMD $-2 \cdot 17$ [-4.26 to $-0 \cdot 08] ; \mathrm{p}=0 \cdot 042$; table 3 ).

In the CBR plus facility-based care group, $71(90 \%)$ of 79 participants reached minimum adequate CBR participation ( $\geq 10$ visits), whereas $40(51 \%)$ of 79 participants reached optimal CBR participation ( $\geq 21$ visits). One or more meetings to mobilise specific community resources was held for 45 (57\%) of 79 participants. All core community mobilisation tasks were completed in $21(88 \%)$ of 24 of intervention subdistricts. One or more event raising public awareness was held in 23 (96\%) of 24 subdistricts. However, a public talk by a participant of CBR and employment facilitation took place in only one subdistrict each, and 17 (71\%) of 24 subdistricts had no family support group meetings. The mean ENACTE score was 2.78 (SD 0.19) at baseline and $2.98(0.02)$ at 12 months, indicating that on average CBR workers were rated as "done well" across competencies (table 4).

Overall, four (5\%) of 79 participants in the CBR plus facility-based care group and nine $(10 \%)$ of 87 participants in the facility-based care group had at least one serious adverse event $(\mathrm{p}=0 \cdot 21$; appendix $\mathrm{p} 4)$. Serious adverse events included six deaths (no suicides), two suicide attempts, and six hospitalisations. Data collectors were unmasked during the course of 33 (22\%) of 153 interviews (26 [35\%] of 74 participants in the CBR plus facility-based care group and 7 [9\%] of 79 participants in the facilitybased care group); all unmasking occurred after 12-month WHODAS data had been collected.

Participants with 12-month data available were more likely to be female $(p=0 \cdot 055)$, younger age $(p=0 \cdot 040)$, 


\begin{tabular}{|c|c|}
\hline & $\begin{array}{l}\text { Median (IQR), } \\
\text { mean (SD), } \mathrm{n}(\%) \\
\text { or } \mathrm{n} / \mathrm{N}(\%)\end{array}$ \\
\hline \multicolumn{2}{|l|}{ Participant level ( $n=79)$} \\
\hline \multicolumn{2}{|l|}{ Number of home visits } \\
\hline Phase 1 & $8(7-9)$ \\
\hline Phase 2 & $9(8-11)$ \\
\hline Phase 3 & $4(4-5)$ \\
\hline Total & $21(18-25)$ \\
\hline Minimum adequate CBR participation ( $\geq 10$ visits) & $71(90 \%)$ \\
\hline Optimal CBR participation ( $\geq 21$ visits) & $40(51 \%)$ \\
\hline Months of CBR & $12 \cdot 0(11 \cdot 4-12 \cdot 6)$ \\
\hline Continuous receipt of CBR ( $\geq 1$ home visit/month) & $36 / 77(47 \%)$ \\
\hline Undertook all core modules & $74(94 \%)$ \\
\hline Number of indicated modules undertaken & $5(4-6)$ \\
\hline Started $\geq 75 \%$ indicated modules & $65 / 73(89 \%)$ \\
\hline Achieved all core (standard) goals & $70(89 \%)$ \\
\hline \multicolumn{2}{|c|}{$\begin{array}{l}\text { Number of individual community mobilisation meetings relating to } \\
\text { participant }\end{array}$} \\
\hline 0 meetings & $34(43 \%)$ \\
\hline 1 meeting & $16(20 \%)$ \\
\hline 2 meetings & $11(14 \%)$ \\
\hline$\geq 3$ meetings & $18(23 \%)$ \\
\hline \multicolumn{2}{|l|}{ Subdistrict level $(n=24)$} \\
\hline $\begin{array}{l}\text { All core community mobilisation tasks completed } \\
\text { (resources and leaders identified, awareness raising } \\
\text { with leaders and public) }\end{array}$ & $21(88 \%)$ \\
\hline \multicolumn{2}{|l|}{ Number of public awareness raising meetings } \\
\hline 0 meetings & $1(4 \%)$ \\
\hline $1-2$ meetings & $6(25 \%)$ \\
\hline $3-4$ meetings & $10(42 \%)$ \\
\hline 5-7 meetings & $7(29 \%)$ \\
\hline Public talk by CBR participant & $1(4 \%)$ \\
\hline \multicolumn{2}{|l|}{ Number family support group meetings } \\
\hline 0 meetings & $17(71 \%)$ \\
\hline 1-2 meetings & $3(13 \%)$ \\
\hline$\geq 3$ meetings & $4(17 \%)$ \\
\hline Employment opportunities identified & $2(8 \%)$ \\
\hline Employment opportunities facilitated & $1(4 \%)$ \\
\hline \multicolumn{2}{|l|}{ CBR worker level $(n=11)$} \\
\hline Externally assessed ENACT score trial baseline & $2.78(0.19)$ \\
\hline Externally assessed ENACT score trial at 12 months & $2.98(0.02)$ \\
\hline \multicolumn{2}{|c|}{$\begin{array}{l}\mathrm{CBR}=\text { community-based rehabilitation. } \mathrm{ENACT}=\text { Enhancing Assessment of } \\
\text { Common Therapeutic Factors-Ethiopia. Percentages might not equal 100\% due t } \\
\text { rounding. }\end{array}$} \\
\hline
\end{tabular}

lower socio-economic status $(\mathrm{p}=0 \cdot 032)$, rural residents $(\mathrm{p}=0 \cdot 058)$, have longer illness duration $(\mathrm{p}=0 \cdot 080)$, fewer relapses $(\mathrm{p}=0 \cdot 042)$, and lower caregiver burden $(\mathrm{p}=0 \cdot 024$; appendix pp 5-6). There was evidence of effectmodification by alcohol use disorder, with a greater effect on illness severity among participants with alcohol use disorder than without ( $\mathrm{p}$ value for interaction $=0 \cdot 017$; appendix $p$ 6). There was no evidence of effect modification by other variables on WHODAS score or illness severity (appendix pp 6-7). The findings were similar under sensitivity analyses (appendix pp 7-17). At 12 months, the intra-cluster correlation for WHODAS was $0 \cdot 02(95 \%$ CI $0 \cdot 00-0 \cdot 18)$.

\section{Discussion}

To our knowledge, RISE is the first randomised trial to evaluate the effectiveness of any psychosocial intervention for people with schizophrenia in a low-income country, and it is the first to evaluate a psychosocial intervention as an adjunct to task-shared facility-based care in any setting globally. The inclusion of structured community mobilisation components is unique among randomised evaluations. In this care model, CBR was effective in reducing disability (particularly in relation to participation, social interactions, and cognition), symptom severity, caregiver tension and worrying; and in increasing antipsychotic medication adherence and attendance to facility-based care among people with schizophrenia. However, we found no evidence that CBR impacted on physical restraint, discrimination, employment or work, and household and self-care aspects of disability. The benefits of CBR were only evident after 12 months of the study. Intervention fidelity was good in terms of the number and content of CBR home visits and CBR worker competence.

Findings from the PRIME cohort study showed that access to task-shared facility-based care significantly improved symptom severity, disability, discrimination, and physical restraint over a 12-month period. ${ }^{11}$ Our results demonstrate that a supplementary level of care, CBR, can increase the benefits of facility-based care and produce additional impacts on disability and symptoms in people with schizophrenia who have not responded to or engaged with standard care. We propose that CBR achieved its impact on disability in two ways. First, by maximising engagement with facility-based care; therefore, facilitating the use of antipsychotic medication. Medication adherence could have a positive effect on clinical severity, which might contribute to improved functioning. The strongest intervention effects were seen on facility attendance, medication adherence, and symptoms, suggesting this pathway could have had a prominent role. Descriptive analysis showed that at 12 months a greater proportion of participants in the CBR plus facility-based care group were prescribed medication and had access to free medication than participants in the facility-based care group. We suggest the CBR workers' success is attributable to a combination of mobilising support for transportation to health care, therefore minimising barriers related to geographical accessibility; obtaining medication fee waivers, which increased affordability; psychoeducation (promoting understanding of the potential advantages of treatment), thereby increasing acceptability; and appointment reminders and timely 
referral for relapse and medication side-effects, which optimised the adequacy of care.

Second, CBR might shape an individuals' social environment, indicated by the strongest positive effects on WHODAS domains "getting along" and "participation". Cognitive performance, which showed weaker positive effects, also predicts community independence. ${ }^{23}$ As the main care providers, family members have a powerful influence on illness experience and social roles. We suggest that, as the pilot study demonstrated, ${ }^{10}$ emphasising human rights facilitated attitudinal shifts within families, which in turn promoted participation. Community mobilisation, including raising awareness and engagement with community members to mobilise support, was generally comprehensive and might have facilitated social inclusion. Pathways to improved functioning are likely to be synergistic; social networks were encouraged to support transportation to, and the costs of, facility-based care. However, the absence of an effect on employment, discrimination, and restraint, suggests that impacts on the wider social environment were partial, which might be explained by the nonimplementation of some community activities, such as public talks by participants. The quality of community mobilisation or actual resources mobilised were not assessed. Restrained individuals might reflect a subgroup with refractory illness who require more specialist interventions. The low prevalence of restraint made it challenging to detect an intervention effect; furthermore, improvements in work-related functioning, discrimination, and restraint might require attitude and behaviour changes that emerge beyond 12 months. We anticipate future qualitative analyses will be central to understanding the extent that community resources were actually mobilised, reasons for difficulties, and the impact on recovery. ${ }^{24}$

Although non-significant in sensitivity analyses, the adverse impact of CBR on unemployment deserves scrutiny. Vocational skills training and microfinance are often included in CBR programmes and similar models. ${ }^{7}$ RISE omitted similar livelihood support due to sustainability concerns, instead including optional support to resume farming and identification of employment opportunities. However, employment opportunities are scarce..$^{10}$ Furthermore, employment status is a crude measure of economic impact and household economic status might be a superior measure.

There were missing data on the self-rated WHODAS and BPRSE due to participants being too unwell to respond. Lower power to detect intervention effects might explain the difference with proxy-rated WHODAS and CGI scores, which do not rely on self-reporting. The tendency of people with schizophrenia to overestimate functioning compared with external assessment has also been reported. ${ }^{16,25}$ The lack of effect on the BFS could be because of the large proportion of work-related items. ${ }^{19}$
The absence of impact on caregiver depression is not surprising since caregivers did not receive an evidencebased intervention; however, the effects on worrying and tension demonstrate that the emotional burden of caregiving can be alleviated by an intervention primarily targeting their relative.

Our findings reflect the benefits of community-based psychosocial interventions found in middle-income country settings. ${ }^{3,626-28}$ The COPSI RCT of collaborative community-based care in India represents the most comparable previous evaluation. ${ }^{6}$ However, reflecting standard care in that context, all COPSI participants received regular psychiatrist reviews and free antipsychotic medication. Our results show that layworker delivered psychosocial interventions are also effective when delivered alongside task-shared facilitybased care (delivered by non-physicians), as promoted by WHO Mental Health Gap Action Programme, and when free antipsychotic medication is not universally available. Furthermore, despite relying on non-specialist supervisors (a novel feature contrasting with psychiatric social worker supervision in $\mathrm{COPSI}^{6}$ ) no concerns around participant safety or CBR worker competence were identified in this analysis. We have shown that participation rates are high and that CBR is effective in an area highly reliant on time-consuming subsistence farming, where many participants reside in remote areas, and where there are few material resources to access treatment or support recovery. As such, we have demonstrated that CBR is generalisable to low-income country settings, even when modified to match available mental health-care infrastructure.

On the basis of our current findings, we propose a holistic psychosocial intervention, encompassing support with treatment engagement and efforts to shape the social environment. Planned exploratory and qualitative analyses will help to determine the active components of CBR and might allow the intervention to be rationalised. The absence of beneficial effects at 6 months suggests prolonged participation is needed to establish relationships and support meaningful changes in behaviour; therefore, we propose a minimum 12 -month intervention is required. We acknowledge that CBR was delivered by a new cadre of workers; as such, the model is not immediately scalable in Ethiopia. However, our study provides an important proof of concept; lay workers after 5 weeks of training and 6 months of work experience can address important aspects of the complex needs of people with schizophrenia. Incorporating mental health into the work of existing community health workers has proved difficult because of their high occupational load; ${ }^{29}$ the use of health extension workers to deliver CBR was discounted early on for this reason. ${ }^{9}$ Increased numbers of generic community health workers might address these difficulties. Alternatively, the development of new cadres of community-based non-specialist workers, 
including peer supporters, could be key to achieving universal health coverage for people with schizophrenia. ${ }^{1,24}$ Mental health can also be integrated into existing CBR programmes, ${ }^{30}$ although, coverage might be limited.

Study limitations include the lack of assessment for an enduring impact of CBR after the intervention had terminated and the relatively large number of outcomes. Each of these was prespecified in the analysis plan because of the potential association with the intervention; and we have been conservative in our interpretation. However, it is possible that some of these associations arose due to chance. Outcomes measured in community members-eg, discrimination-would help to elucidate the utility of community mobilisation. Finally, the resource implications of CBR are currently unknown.

In conclusion, we have shown that psychosocial support can promote functional recovery of people with schizophrenia in a low-income country and demonstrated the feasibility of lay worker delivery. Further research should investigate large-scale implementation of models such as this.

\section{Contributors}

LA drafted the report, which all the authors reviewed and approved. LA, AF, CH, MDS, GM, HAW, and VP designed the trial. LA, AF, CH, MDS $\mathrm{RB}$, and VP devised the intervention content and data collection instruments. LA, AF, and RB were responsible for trial conduct. LA and $\mathrm{RB}$ were responsible for database design and management. LA and HAW did the statistical analyses. LA and HAW have verified the underlying data.

\section{Declaration of interests}

$\mathrm{CH}$ reports support from the National Institute of Health Research (NIHR) through a RIGHT grant (NIHR200842) and the NIHR Global Health Research Unit on Health System Strengthening in sub-Saharan Africa, King's College London (GHRU 16/136/54), using aid from the UK Government; and support from African Mental Health Research Initiative as part of the Developing Excellence in Leadership, Training, and Science Africa Initiative (DEL-15-01). HAW reports support from the UK Medical Research Council (MRC) and the UK Department for International Development (DFID) under the MRC-DFID concordat agreement, which is also part of the European and Developing Countries Clinical Trials Partnership programme 2 supported by the EU (MR/R010161/1). All other authors declare no competing interests. The views expressed in this publication are those of the authors and not necessarily those of the NIHR or the Department of Health and Social Care.

\section{Data sharing}

Anonymised participant data and a data dictionary will be made available by 12 months after publication. Data will be shared following a reasonable submitted request and approval by the corresponding author. The study protocol and statistical analysis are publicly available. ${ }^{12}$

\section{Acknowledgments}

This work was supported by the Wellcome Trust Fellowship in International Health $[100142 / \mathrm{Z} / 12 / \mathrm{Z}]$ awarded to LA. The RISE project is part of the Programme for Improving Mental Health Care (PRIME), which was funded by the UK Department for International Development for the benefit of LMICs [HRPC10]. We thank the CBR workers and CBR supervisors who supported the implementation of the trial and the participating individuals.

\section{References}

1 Patel V. Universal health coverage for schizophrenia: a global mental health priority. Schizophr Bull 2016; 42: 885-90.

2 Lora A, Kohn R, Levav I, McBain R, Morris J, Saxena S. Service availability and utilization and treatment gap for schizophrenic disorders: a survey in 50 low- and middle-income countries. Bull World Health Organ 2012; 90: 47-54, 54A-54B.
3 Asher L, Patel V, De Silva MJ. Community-based psychosocial interventions for people with schizophrenia in low and middleincome countries: systematic review and meta-analysis. BMC Psychiatry 2017; 17: 355

4 WHO. Community based rehabilitation: CBR guidelines. Geneva: World Health Organization, 2010. https://www.who.int/ publications/i/item/9789241548052 (accessed March 1, 2021).

5 WHO. mhGAP Intervention Guide for mental, neurological and substance use disorders in non-specialized health settings Version 2.0. Geneva: World Health Organization, 2016. https://www.who. int/publications/i/item/9789241549790 (accessed March 1, 2021).

6 Chatterjee S, Naik S, John S, et al. Effectiveness of a communitybased intervention for people with schizophrenia and their caregivers in India (COPSI): a randomised controlled trial. Lancet 2014; 383: 1385-94.

7 Lund C, Waruguru M, Kingori J, et al. Outcomes of the mental health and development model in rural Kenya: a 2-year prospective cohort intervention study. Int Health 2013; 5: 43-50.

8 Chatterjee S, Pillai A, Jain S, Cohen A, Patel V. Outcomes of people with psychotic disorders in a community-based rehabilitation programme in rural India. Br J Psychiatry 2009; 195: 433-39.

9 Asher L, Fekadu A, Hanlon C, et al. Development of a communitybased rehabilitation intervention for people with schizophrenia in Ethiopia. PLoS One 2015; 10: e0143572.

10 Asher L, Hanlon C, Birhane R, et al. Community-based rehabilitation intervention for people with schizophrenia in Ethiopia (RISE): a 12 month mixed methods pilot study. BMC Psychiatry 2018; 18: 250.

11 Hanlon C, Medhin G, Selamu M, et al. Impact of integrated district level mental health care on clinical and social outcomes of people with severe mental illness in rural Ethiopia: an intervention cohort study. Epidemiol Psychiatr Sci 2019; 29: e45.

12 Asher L, De Silva M, Hanlon C, et al. Community-based rehabilitation intervention for people with schizophrenia in Ethiopia (RISE): study protocol for a cluster randomised controlled trial. Trials 2016; 17: 299.

13 McGuffin P, Farmer A, Harvey I. A polydiagnostic application of operational criteria in studies of psychotic illness. Development and reliability of the OPCRIT system. Arch Gen Psychiatry 1991; 48: 764-70.

14 Asher L, Birhane R, Teferra S, et al. "Like a doctor, like a brother": achieving competence amongst lay health workers delivering community-based rehabilitation for people with schizophrenia in Ethiopia. PLoS One 2021; 16: e0246158.

15 WHO. Measuring health and disability: manual for WHO disability assessment schedule (WHODAS 2.0). Geneva: World Health Organization, 2010.

16 Habtamu K, Alem A, Medhin G, et al. Validation of the World Health Organization disability assessment schedule in people with severe mental disorders in rural Ethiopia. Health Qual Life Outcomes 2017; 15: 64.

17 Mortimer AM. Symptom rating scales and outcome in schizophrenia. Br J Psychiatry Suppl 2007; 50: s7-14.

18 Ruggeri M, Koeter M, Schene A, et al. Factor solution of the BPRS-expanded version in schizophrenic outpatients living in five European countries. Schizophr Res 2005; 75: 107-17.

19 Habtamu K, Alem A, Medhin G, Fekadu A, Prince M, Hanlon C. Development and validation of a contextual measure of functioning for people living with severe mental disorders in rural Africa. BMC Psychiatry 2016; 16: 311

20 Susser E, Finnerty M, Mojtabai R, et al. Reliability of the life chart schedule for assessment of the long-term course of schizophrenia. Schizophr Res 2000; 42: 67-77.

21 Thornicroft G, Brohan E, Rose D, Sartorius N, Leese M. Global pattern of experienced and anticipated discrimination against people with schizophrenia: a cross-sectional survey. Lancet 2009; 373: 408-15

22 Hanlon C, Medhin G, Selamu M, et al. Validity of brief screening questionnaires to detect depression in primary care in Ethiopia. J Affect Disord 2015; 186: 32-39.

23 Heinrichs RW, Ammari N, Miles AA, McDermid Vaz S. Cognitive performance and functional competence as predictors of community independence in schizophrenia. Schizophr Bull 2010; 36: $381-87$. 
24 Kohrt BA, Asher L, Bhardwaj A, et al. The role of communities in mental health care in low- and middle-income countries: a metareview of components and competencies. Int J Environ Res Public Health 2018; 15: E1279.

25 Sabbag S, Twamley EW, Vella L, Heaton RK, Patterson TL Harvey PD. Predictors of the accuracy of self assessment of everyday functioning in people with schizophrenia. Schizophr Res 2012; 137: 190-95.

26 Li J, Huang YG, Ran MS, et al. Community-based comprehensive intervention for people with schizophrenia in Guangzhou, China: effects on clinical symptoms, social functioning, internalized stigma and discrimination. Asian J Psychiatr 2018; 34: 21-30.

27 Luo X, Law SF, Wang X, et al. Effectiveness of an assertive community treatment program for people with severe schizophrenia in mainland China-a 12-month randomized controlled trial. Psychol Med 2019; 49: 969-79.
28 Chen Y, Yau E, Lam C, et al. A 6-month randomized controlled pilot study on the effects of the clubhouse model of psychosocial rehabilitation with Chinese individuals with schizophrenia. Adm Policy Ment Health 2020; 47: 107-14.

29 Fuhr DC, Weobong B, Lazarus A, et al. Delivering the thinking healthy programme for perinatal depression through peers: an individually randomised controlled trial in India. Lancet Psychiatry 2019; 6: 115-27.

30 Koly KN, Abdullah R, Shammi FA, et al. Mental health and community-based rehabilitation: a qualitative description of the experiences and perspectives of service users and carers in Bangladesh. Community Ment Health J 2022; 58: 52-66 